\title{
Understanding Moral Disagreement: A Christian Perspectivalist Approach
}

\author{
Blake McAllister (iD
}

Citation: McAllister, Blake. 2021. Understanding Moral Disagreement: A Christian Perspectivalist Approach. Religions 12: 318. https://doi.org/ $10.3390 /$ rel12050318

Academic Editors: J. Caleb Clanton and Kraig Martin

Received: 8 April 2021

Accepted: 29 April 2021

Published: 30 April 2021

Publisher's Note: MDPI stays neutral with regard to jurisdictional claims in published maps and institutional affiliations.

Copyright: (C) 2021 by the author. Licensee MDPI, Basel, Switzerland. This article is an open access article distributed under the terms and conditions of the Creative Commons Attribution (CC BY) license (https:/ / creativecommons.org/licenses/by/ $4.0 /)$.
Department of Philosophy \& Religion, Hillsdale College, Hillsdale, MI 49242, USA; bmcallister@hillsdale.edu

\begin{abstract}
Deep moral disagreements exist between Christians and non-Christians. I argue that Christians should resist the temptation to pin all such disagreements on the irrationality of their disputants. To this end, I develop an epistemological framework on which both parties can be rational-the key being that their beliefs are formed from different perspectives and, hence, on the basis of different sets of evidence. I then alleviate concerns that such moral perspectivalism leads to relativism or skepticism, or that it prohibits rational discourse. I end by exploring new avenues for resolving deep moral disagreements opened up by the perspectivalist approach.
\end{abstract}

Keywords: moral disagreement; moral perspectivalism; peer disagreement; phenomenal conservatism

\section{Introduction}

It is a platitude, I take it, that moral disagreements exist between those who keep the historic and apostolic Christian faith, who I will call "Christians," and those who do not, who I will call "non-Christians." ${ }^{1}$ Neither of these groups is monolithic, naturally. My opening observation is simply that certain moral beliefs are prevalent among (important subsets of) Christians and non-Christians, respectively, and that these beliefs sometimes contradict one another. The extent to which these parties disagree should not be overstated, of course. Many moral principles enjoy widespread endorsement within and without the Christian community. Additionally, many of the disagreements that do exist are only surface deep — that is, the disagreement stems from a discrepancy concerning non-moral facts such that were the interlocutors to come to agreement on these non-moral facts, the disagreement would be resolved. Abortion is often taken to be an example of surface disagreement, and perhaps it sometimes is: if Christians and non-Christians came to an agreement on when life or personhood originates, then they might also reach agreement on the morality of abortion. In some instances, however, the disagreement is not so readily resolved.

For example, following Judith Jarvis Thompson, many non-Christians maintain that abortion is moral even if the fetus is a human person, insisting that the woman's bodily autonomy frees her from any obligation to lend herself in sustaining the life of another. ${ }^{2}$ Others, following Peter Singer, argue that the moral significance of any person is directly proportioned to the level of sentience it has attained. Hence, persons in utero (or even infants) can be permissibly killed if their continued existence significantly harms those with a greater capacity for pleasure or pain. ${ }^{3}$ Thus we see that agreement on the biological and even metaphysical facts of the situation does not always resolve disagreement on the morality of abortion. Such cases - ones where there is a dispute over moral principles, not just their application-are instances of deep moral disagreement.

Deep moral disagreements are more common than one might think, often being obscured by the use of similar terminology. "Love," for instance, is a virtue ostensibly championed by Christians and (many) non-Christians alike. However, it becomes readily apparent in application that the Christian and non-Christian conceptions of love can differ greatly from one another. On the latter conception, the loving thing may be that which 
promotes the fulfillment of one's sincerely held desires, whatever they may be. While on the former conception, loving someone may require encouraging them to relinquish certain desires in pursuit of sanctification. Such differences are rooted in rival accounts of human well-being. Here, terminological similarities hide deep moral disagreement.

Deep disagreement can also be obscured by the pervasive influence of Christianity on Western culture. How easy it is to forget that certain moral principles taken for granted in the West today were not so obvious to those of a different time or place. Belief in the inherent dignity and equality of all men and women, for instance, was present in few if any pagan cultures. Indeed, Nietzsche applauds the vigor of an elitist society that "accepts in good conscience the sacrifice of countless people who have to be pushed down and shrunk into incomplete human beings, into slaves, into tools, all for the sake of the aristocracy." ${ }^{\prime 4}$ Or consider Singer's position that infanticide is sometimes morally permissible. Those who would claim that this position is evidently false to any morally sane individual should consider that the greatest moral theorists of antiquity, Plato and Aristotle, licensed the exposing of deformed infants. Singer insightfully writes, "If these conclusions appear too shocking to take seriously, it may be worth remembering that our present absolute protection of the lives of infants is a distinctively Christian attitude rather than a universal ethical value.. ${ }^{5}$ We must not mistake the moral insights of Christianity for truisms. Thinkers like Singer and Nietzsche are helpful in breaking the illusion of banality.

There is a temptation for Christians to pin such disagreements on irrationality. After all, if moral disagreements can be both deep and reasonable, then uncomfortable questions are raised. Does the existence of reasonable disagreement imply moral relativism? More plausibly, does it undermine justification for our own moral beliefs? Does it stifle hope that the disagreement can be resolved through moral discourse?

It is surely the case that many deep disagreements stem from bias, fallacious reasoning, or other failures in one's duty to pursue truth and avoid falsehood. However, Christians should avoid the temptation of charging all who dissent with irrationality of this sort. I will assume here that at least some non-Christians are justified in their moral beliefs, even when those beliefs directly contradict the Christian position. This is a fact about moral disagreement that Christians must face squarely. My goal in this paper is to develop an epistemological approach that charitably acknowledges the possibility of reasonable moral disagreement while avoiding the worries sometimes thought to accompany it. ${ }^{6}$ It leads neither to relativism nor skepticism, nor does it deny the possibility of fruitful moral discourse. What it does do is illuminate why ordinary moral discourse between reasonable individuals can often reach something of an impasse, as well as shed light on how such apparent impasses may in fact be resolved. The crux is that a reorientation in perspective is needed-discursive reasoning alone is not enough.

The approach that I defend is a version of moral perspectivalism. The name signifies that the justification of one's moral beliefs is ultimately determined by the perspective from which one makes those judgments; thus, differences in perspective explain how conflicting moral beliefs can both be justified. My particular version of moral perspectivalism is grounded in an epistemological framework I call "seemings foundationalism." I address common concerns with moral perspectivalism in section two, and draw out important lessons for resolving disagreement in section three.

\section{Seemings Foundationalism}

The purpose of this section is to introduce a rough sketch of seemings foundationalism and show how it accounts for deep and reasonable moral disagreement. As a form of foundationalism, seemings foundationalism maintains that all inferential justification ultimately arises from the non-inferential justification afforded to basic beliefs. Different forms of foundationalism differ concerning what provides non-inferential justification and how. True to its name, seemings foundationalism says that non-inferential justification derives entirely from how things seem to the subject. This breaks down into two epistemic principles. The first is phenomenal conservatism: 
PC: If it seems to $S$ that $p$, then, in the absence of defeaters, $S$ thereby has at least some degree of justification for believing that $p .{ }^{7}$

The second is seemings exclusivism:

SE: $S$ has some degree of immediate justification for believing that $p$ only if it seems to $S$ that $p$.

In short, all and only appearances, or "seemings," provide non-inferential justification. I do not have the space to argue for seemings foundationalism here, though I will seek to make it plausible. To do so, let us first turn our attention to these mental states, seemings, that supposedly ground all justification.

Seemings are a kind of experience-one in which a propositional content is presented to the subject as true. ${ }^{8}$ Consider a case where you are in pain. You attend to that pain and think, "I am in pain." How do you know that thought to be true? The answer is that you can simply see that it is-you are directly acquainted with the correspondence between that content and the state of affairs it represents. There is a certain kind of feeling, or phenomenal character, that accompanies one's thought in such situations. The thought's content feels true. When a proposition feels this way, we call it "obvious," or "evident," or "manifest," or we might simply say "it seems true."

Introspection is not the only area in which things seem true. In perception, for instance, one's perceptual experiences feel as though they are accurately representing the way things are in one's immediate physical environment. There is a feeling of correspondence between the content of our perceptual experience and the world which it describes. Something similar is true in cases of rational intuition. It feels as though there is a correspondence between the content of some thought and the logical, mathematical, or metaphysical facts at issue. Importantly for us, there are also moral intuitions which display these same characteristics. For instance, it may seem evident to you that infanticide is a grave moral evil. Here, as before, there is a felt correspondence between some thought and a fact in the world (in this case, a moral fact). These are all different varieties of the same basic kind of state, namely, seemings.

A rough argument for seemings foundationalism goes as follows. Beliefs are noninferentially justified only if the mental state that causes them psychologically also justifies them epistemically. This is the nature of doxastic justification-that is, a belief is justified only if it is properly based on that which propositionally justifies its content. Furthermore, since this is a case of non-inferential justification, the state that causes and justifies belief must do so immediately, without reliance on a larger system of justified background beliefs. Notice that, on foundationalism, some beliefs or other must be immediately justified in this way lest there be nothing justified at all. The question to ask then is what kind of states are capable of both psychologically motivating and epistemically justifying belief in this immediate manner?

There are really only two basic ways to psychologically motivate belief: by indicating that some content is true or by indicating that it is good that it be true. States that motivate in the latter way (emotions, desires, and other affective states) are not capable of justifying. ${ }^{9}$ Therefore, whatever mental states immediately justify basic beliefs must do so by indicating that the content is true. Such indication must be intrinsic as well-that is, the mental state $\mathrm{M}$ cannot indicate the truth of proposition $\mathrm{p}$ only because the subject has some surrounding framework of justified background beliefs which inform her that $\mathrm{M}$ makes $\mathrm{p}$ likely.

Seemings fit the bill here. By phenomenally presenting their content as true, seemings intrinsically indicate the truth of their content. They are the kind of state that not only does motivate belief but should motivate belief for those concerned to pursue truth and avoid falsehood. Since all seemings share this same phenomenological character, albeit in differing strengths, all seemings thereby provide some degree of immediate justification for their content. This is phenomenal conservatism. 
Are any other kinds of states capable of intrinsically indicating the truth of some content? It seems not. If they lack propositional content, then the subject will not be able to appreciate the connection between that mental state and the content to be believed without a system of justified background beliefs in place. If they possess propositional content, but lack the feel of truth, then they will not intrinsically indicate the truth of that content in the right kind of way. A thought that $p$, if it does not feel true, only indicates the truth of $p$ if one has reason to believe that the possession of that thought is in some way a sign of p's truth; but that relies on a system of justified background beliefs and so is not an intrinsic indication of p's truth. Finally, if the states at issue possess propositional content and the feel of truth, then they are just species of seemings. Thus, it seems that only seemings are capable of immediately justifying their content. This is seemings exclusivism.

It is important to note that seemings foundationalism is about internalist justification or rationality. This is distinct from warrant, which pertains more to knowledge. A belief is internally justified if, given all of the evidence available to the subject, the content of that belief is on-balance indicated to be true. What is available to the subject is just what features within one's conscious awareness. The focus, then, is on the subject's first-person point of view and whether one's beliefs line up with what is indicated to be true from that perspective. Externalist statuses such as warrant look at things from more of a thirdperson point of view. The details differ by theory, but in outline, a belief is warranted if there is the right kind of connection between one's belief and the matter at hand. For instance, the belief-forming process may need to be reliable (i.e., statistically likely to produce true beliefs), or the belief may need to be produced in a way that tracks the truth (i.e., that is safe or sensitive) or that manifests virtue. The crucial discrepancy here is that warrant does not confine itself to the purview of the subject. One may have no indication whatsoever that one's belief is unreliable, or unsafe, or un-virtuous-even so, one's belief is thereby unwarranted. Our primary focus in this paper will be on internal justification and rationality, although familiarity with warrant will be helpful as well.

Seemings foundationalism can help us understand the origins and significance of deep moral disagreement. The first thing to note is that all of our justified moral beliefs (and any other belief, for that matter) will ultimately be based on seemings. If the moral belief is basic, then it is based directly on moral intuition. For instance, the belief that it is wrong to deliberately harm others when there is no greater good gained nor evil avoided is plausibly believed simply because it seems obviously true. If the moral belief is non-basic, then one's belief is based on other beliefs, usually some combination of moral and non-moral beliefs. For instance, say you conclude that it is wrong to torture another person for fun. Presumably, you will have inferred this from the foundational principle that it is wrong to deliberately harm others when there is no greater good gained nor evil avoided, along with the beliefs that torture causes harm, that the fun of the torturer is not a greater good" etc. What are these other beliefs based on? Eventually, we must trace the inferential chain back to basic beliefs that are based on how things appear. ${ }^{10}$

The next thing to note is that how things appear can differ considerably from person to person. What seems obviously wrong to a Christian may not to a non-Christian. We can describe this by saying that different people have different moral perspectives. A perspective is a set of firm and lasting dispositions for things to seem a certain way. Effectively, one's perspective determines which seemings one counts as possessing.

All of this leads to a natural explanation for deep moral disagreement. Moral beliefs differ because moral intuitions do-because Christians and non-Christians are operating from different moral perspectives. Furthermore, where intuitions differ there is some possibility that both parties to the dispute are proceeding rationally in accordance with how things seem to them. This is not guaranteed, of course. It will often be the case that one or more of the disputants is failing to recognize a conflict between their beliefs, or lending too much or too little weight to some intuition, or making some one of many possible errors. ${ }^{11}$ The point is that it is possible that neither party is making any mistake at all. They simply see things differently and, from those different moral perspectives, rationally reach 
different conclusions. Thus, seemings foundationalism accounts for deep and reasonable moral disagreement.

Now, if seemings can differ in these opposing ways, then some of them must be wrong. This should not be surprising. Seemings are fallible. It is to be expected, then, that some people's seemings align better with reality than others. This does not change the fact that, from an internal point of view, we must give appearances the benefit of the doubt in our theorizing. Thus, unless we have some indication that they are misleading, the rational thing is to believe in accordance with one's moral intuitions, even if they are (from a more external point of view) flawed.

That being said, if one's beliefs are based on faulty appearances, then that will likely affect the warrant of the resulting beliefs. The beliefs may be rational (internally) but unwarranted (externally). In such cases, there is indeed something wrong with one's beliefs, but the problem is not irrationality per se. One has not feigned one's duties in the pursuit of truth or stupidly miscalculated. The error lies not in the subject's handling of the evidence but in the unreliable or misleading nature of the evidence itself.

This provides us with a charitable way of diagnosing error within those who disagree with the Christian community. We can, if called for, acknowledge the rationality of their beliefs. They have, we can concede, reached precisely the conclusion that makes the most sense given their moral perspective. The problem, rather, is that the way things seem to them is out of joint with how things really are. Their perspective is skewed. Moreover, this need not be due to any deep flaw within them (though in some cases that may be part of the explanation), but could simply be the result of participating in a flawed tradition.

\section{Common Objections to Moral Perspectivalism}

The perspectivalist explanation of disagreement makes some Christians feel uncomfortable. It smells like relativism to some. Or if not relativism, then at least skepticism. How can we acknowledge the rationality of non-Christians in reaching different conclusions and still be reasonably confident that we are getting it right and not them? Allow me to quell these fears.

First is the charge of relativism. The worry here is that acknowledging the rationality of Christians and non-Christians in believing $\mathrm{p}$ and not-p, respectively, implies that there is no objective fact of the matter. However, that does not follow at all. The following argument is plainly a bad one:

1. Some Christians rationally believe $p$, and some non-Christians rationally believe not-p.

2. Thus, there is no objective truth about whether $\mathrm{p}$.

The mere fact that there is reasonable disagreement about something does not entail anything about its objectivity. This is especially obvious when we begin comparing reasonable disagreement across history. An ancient Mesopotamian may have been perfectly rational in believing that the earth was flat, but this in no way suggests that the shape of the earth is relative. One may protest that the ancient Mesopotamians had an entirely different set of evidence than us; what is disturbing, however, is when people living at the same time reasonably disagree. This response misses the key insight of seemings foundationalism, which is that people today are also working with different sets of evidence-in some cases quite different-because they see the world from different perspectives. In this way, the disagreement between people today is not that disanalogous from the disagreement between us and the Mesopotamians.

The only way to connect the lack of agreement to the lack of objective truth is by introducing some expectation concerning our access to objective truth. The idea here is that if there were an objective truth about $\mathrm{p}$, then everyone would have unproblematic cognitive access to that truth such that reasonable disagreement would not be possible. In simply stating such a principle, one cannot help but see its implausibility. Why should we expect the world to be transparent to us? We might like it if that were the case, and perhaps some upstart youths manage to convince themselves that they have a perfect cognitive grasp of 
everything, but age and experience is humbling (humiliating?) and readily convicts us of our finitude.

A more understandable concern is that moral perspectivalism shows our access to objective truth to be problematic, perhaps in insuperable ways. This is the threat of skepticism, and it can be developed in a few different ways. The first arises most notably from Kant and the philosophical tradition that follows him. The suggestion here is that acknowledgment of the ways in which our perspectives necessarily infiltrate the beliefforming process (there is no view from nowhere) shows that what we have access to is the world as we perceive it, not the world as it really is. Thus, while objective reality may be "out there" in some sense, it is not accessible to us. The second concern that the existence of disagreement shows the Christian moral perspective to be unreliable. The third is that we have no good reason to think the Christian perspective more reliable than any other, in which case we should conciliate and become agnostic on points of disagreement. I will address each of these in turn.

The Kantian argument (though Kant would not have framed things in these terms) begins by recognizing that our moral beliefs are always formed from a certain perspective. Kant himself might emphasize the ways in which the concepts and assumptions underlying our perspectives arise necessarily from the nature of rationality and the structure of rational cognition; others may emphasize the contingency of our perspectives and the ways in which they are shaped by our various cultures, linguistic frameworks, and lived-experiences. In either case, the argument says that because we can only approach reality from a particular perspective, what we are grasping is not objective reality itself but at most a subjective reality molded by our perspective.

This line of reasoning faces numerous difficulties. For one, it is self-undermining. Am I to accept the conclusion as something that is known to be true about the world as it really is? If so, then the conclusion refutes itself. If not, then why should I believe it? A similar point could be made about the reasoning leading to that conclusion. As Thomas Reid says, "He must either be a fool, or want to make a fool of me, that would reason me out of my reason."12

Second, the argument rests on a fundamental conflation between the object grasped and the means of grasping it. Consider the analogy of looking through glasses at a tree. The Kantian argument suggests that, when you look through the lenses, what you see is not actually the tree but rather something like an image of the tree projected onto the lenses. The means by which you are supposed to access reality-the lens-becomes the object of perception. To the contrary, as C.S. Lewis writes, "the whole point of seeing through something is to see something through it." ${ }^{13}$ What is perceived in this situation is the tree-an object whose existence and character is completely independent of the lenses through which you are looking. The lenses simply serve as the medium through which you become acquainted with that lens-independent object. In the same way, one's perspective on the world is simply the way in which one's intellect comes into cognitive contact with mind-independent reality. Our reliance on perspectives does not shut us out from knowing that reality any more than someone's wearing glasses prevents him from seeing the world around him.

The Kantian line is tempting, however, for something like the following reason. The glasses through which I am viewing the tree might have a distorting effect. Perhaps the tree appears blurry or fuzzy. The tree itself is not fuzzy, but what I am perceiving is fuzzy, so what I am perceiving cannot be the tree itself. The error here is thinking that what you are perceiving is fuzzy. What you are perceiving is a tree, and trees (around here at least) are not fuzzy. The tree appears fuzzy to you, granted, but that is different from saying that the object of your perception is, in fact, a fuzzy object. Even if one's perspective presents objective reality as being different than it actually is, the point remains that objective reality is what is being presented to you. That is what you are forming beliefs about, be they true or false. There is no sense in which the requirement that objective reality be presented through a perspective cuts you off from that reality. 
Fine, but the question remains, does the Christian moral perspective present the world to us as it really is or, like a bad pair of glasses, does it distort our view of reality? We might simplify matters by simply asking: Is the Christian perspective reliable? You might think the existence of many different moral perspectives shows that it is not. But how is this argument supposed to go? Acknowledging that the Christian perspective is one among others entails nothing about its reliability. Returning to the glasses analogy, note that glasses do not have to have a distorting effect. To the contrary, those with the right prescription will experience clarification, bringing the world as it really is into sharper focus. The fact that other people with different glasses see things differently does not mean that your glasses are distorting things. Perhaps it is they that have the wrong prescriptions while you have met a skilled optometrist and had your sight corrected. In short, even amongst disagreement, it remains possible that Christians are seeing things reliably.

Even if disagreement does not entail unreliability, it may still provide evidence of it. The burden, however, is on objectors to specify how it is supposed to do so. Perhaps their thinking is as follows:

3. The moral beliefs of Christians and non-Christians, though stemming from different perspectives, ultimately arise from the same basic cognitive processes (the same kinds of rational faculties operating in roughly equivalent ways).

4. Many of the beliefs resulting from these cognitive processes are false, since they contradict one another.

5. If many of the beliefs produced by these cognitive processes are false, then those cognitive process are unreliable.

6. Therefore, the cognitive processes resulting in Christian moral beliefs are unreliable.

This reasoning contains a number of errors. To see that there must be something wrong, notice that the same line of reasoning could be used to undermine many other kinds of beliefs that we take to be reliable. For instance, the various scientific beliefs that people have held across history seem to stem from the same basic cognitive processes, but many of those scientific beliefs (even most of them) have been false. Does that prove that the faculties underlying our scientific beliefs are unreliable? Presumably not. (If so, then we are dealing with a much larger crisis that is not unique to moral beliefs.).

One error is that the argument plays up disagreement too much. There is far more agreement than disagreement concerning moral matters. Thus, even if we grant that "many" of our moral beliefs are false in some sense, premise 5 understood in that same sense would not be plausible. A reliable process might produce many false beliefs so long as it produces many more true ones. For premise 5 to be plausible, we would need to understand the antecedent as stating that some large percentage of the total beliefs produced by those cognitive processes are false, but that interpretation (on any reasonable reading of "large") renders premise 4 implausible given the predominant agreement in moral beliefs.

The objector may try to refocus the argument on the specific cognitive processes at use in areas of disagreement. The cognitive processes underlying contentious moral beliefs may be unreliable even if the general cognitive processes underlying most moral beliefs are not. Narrowing the argument in this way highlights a flaw with premise 3. In areas of deep disagreement, what evidence is there that Christians and non-Christians are relying on the same cognitive processes? If Christianity is true, then the cognitive processes at work in Christians and non-Christians are exceedingly different. In Romans 1, the apostle Paul describes the cognitive processes at work in fallen man.

${ }^{18}$ For the wrath of God is revealed from heaven against all ungodliness and unrighteousness of men, who by their unrighteousness suppress the truth....

${ }^{21}$ For although they knew God, they did not honor him as God or give thanks to him, but they became futile in their thinking, and their foolish hearts were darkened. (Romans 1: pp. 18, 21; ESV) 
Elsewhere, he contrasts this fallen manner of thinking with the one present in Christians.

17 Now this I say and testify in the Lord, that you must no longer walk as the Gentiles do, in the futility of their minds. ${ }^{18}$ They are darkened in their understanding, alienated from the life of God because of the ignorance that is in them, due to their hardness of heart. ... ${ }^{20}$ But that is not the way you learned Christ! $-{ }^{21}$ assuming that you have heard about him and were taught in him, as the truth is in Jesus, ${ }^{22}$ to put off your old self, which belongs to your former manner of life and is corrupt through deceitful desires, ${ }^{23}$ and to be renewed in the spirit of your minds, ${ }^{24}$ and to put on the new self, created after the likeness of God in true righteousness and holiness. (Ephesians 4: pp. 17-18, 20-24; ESV)

The supposed cause of this renewed mind is the Holy Spirit and his work in the minds of believers.

12 Now we have received not the spirit of the world, but the Spirit who is from God, that we might understand the things freely given us by God. ${ }^{13}$ And we impart this in words not taught by human wisdom but taught by the Spirit, interpreting spiritual truths to those who are spiritual. ${ }^{14}$ The natural person does not accept the things of the Spirit of God, for they are folly to him, and he is not able to understand them because they are spiritually discerned. (1 Corinthians 2 : pp. 12-14; ESV)

If Scripture tells truly, then the cognitive processes underlying Christian and nonChristian moral beliefs (at least in these key areas of disagreement) could not be more different. Either the mechanisms themselves are different, with the Holy Spirit functioning as a new kind of cognitive mechanism, or else the operation of one's rational faculties is different, with the Christian's being "renewed" in some way. I have suggested elsewhere that this renewal, which is plausibly a part of faith, may just be the onset of a proper perspective - one that allows the Christian to see the world rightly. ${ }^{14}$

It is also worth noting that the way in which the Spirit might be working is through one's tradition of inquiry. That is, the Spirit may choose to initiate one into a Christian perspective not through mystical experience or miraculous intervention (though those are certainly on the table), but by educating one in the Christian tradition and manner of life. This is carried out through scripture, sermons, and theological training, yes, but also through the liturgy, forms of worship, and witnessing the lives of other Christians.

The essential point is that premise 3 remains doubtful, and in fact contradicts Christian teaching. Nor is there going to be any easy way of shoring up the argument in light of these doubts. If Christianity is true, then the processes underlying Christian moral beliefs are reliable. Thus, establishing the unreliability of those processes will require showing that Christianity is false. This is simply an extension of Alvin Plantinga's thesis concerning belief in Christian doctrine more generally. ${ }^{15}$

The final skeptical worry does not depend on the unreliability of the Christian perspective; rather it proposes that we lack any good reason for thinking that the Christian perspective is more reliable than (some of) the alternatives. According to this objection, Christians and non-Christians are epistemic peers, being in roughly equivalent epistemic positions with respect to moral matters and therefore equally likely to get at the truth. Learning that one disagrees with epistemic peers should, it seems, lead one to conciliate or, at least, to greatly lower one's confidence in the Christian position. ${ }^{16}$

This argument runs into the same problem as the last one. If Christianity is true, then Christians and non-Christians are not epistemic peers. Thus, the Christian who believes in Christian teaching will have reason for thinking that her moral beliefs are more likely to be true. The objector may think such a reason illegitimate. After all, the belief that non-Christian perspectives should be downgraded is itself the product of the Christian perspective. Christians are using the Christian perspective to assure themselves of its special reliability. Is this not like taking a witness's word that she is more trustworthy than 
some other witness who disagrees? What we need, the objector claims, is independent reason for thinking that the Christian perspective is especially reliable.

As natural as it sounds, the objector's demand is unreasonable. First off, what does it mean to have an "independent reason" for thinking the Christian perspective more reliable? All beliefs are formed from a particular perspective. Thus, what is meant by an "independent reason" could only be a reason formed from some non-Christian perspective. But of course, we must then ask why we should think that particular non-Christian perspective to be especially reliable with respect to the matter at hand. Why think it more reliable than the Christian perspective for judging such things (or from some other nonChristian perspective for that matter)? By the objector's criteria, that dispute could only be adjudicated by some additional perspective that is different from the first two, and we quickly embark on an infinite regress. The result is skepticism, since the objector's demand for an "independent reason" can never be legitimately fulfilled.

Is there an alternative? There is. It is, in fact, the approach dictated by seemings foundationalism and its commitment to phenomenal conservatism. It begins with the recognition that one does not need to prove the reliability of one's perspective prior to trusting it. The rational default is to assume the reliability of one's perspectivein belief-formation as if it is reliable - and only to question it when challenges arise. Thus, first-order beliefs about the world are accepted prior to "independent" verification. When serious challenges to one's perspective arise (serious challenges require more than the mere possibility of error), one forms beliefs about the merits of those challenges in the same way as before. That is, one thinks about the matter and forms second-order beliefs about the reliability of one's first-order beliefs on the basis of how things seem. You trust your perspective in the formation of these second-order beliefs just as you do on the first-order. If that reflective process leads you to conclude that your first-order beliefs are unreliable, or even that there is a good chance they are unreliable, then you have defeaters for those beliefs. On the other hand, if this reflective process reassures you of the reliability of your first-order beliefs, then you maintain them as before (You then repeat this pattern as serious challenges to the reliability of your higher-order beliefs arise.).

If we apply this to the case at hand, we see that Christians can be perfectly rational in maintaining their Christian moral beliefs in light of moral disagreement. Imagine a Christian who, with all care and earnestness, reflects on the diversity of moral perspectives. As she reflects, it seems evident to her that the Christian perspective reveals the moral dimensions of reality better than any other, and she realizes that this is exactly what is predicted by Christian teaching and its promise of the Holy Spirit. Based on how things seem to her, she is reassured in the reliability of her original moral beliefs. The rational thing for her to do is to trust that reflective assessment, just as she trusted her moral intuitions in originally forming those beliefs, until there is some reason for thinking otherwise. Say that the reliability of that reflective assessment is itself challenged. Once again, there is nothing else for her to do but reflect on the matter and go with what seems true. So long as the reliability of her lower-order judgments continues to be confirmed, then maintaining her original beliefs continues to be rational. There really is not any other way of proceeding that does not end in skepticism.

Still, the whole process seems circular, which is bothersome. Ultimately, this is something one simply has to get over, though the following observations might help. First, note that there is nothing explicitly circular here-one is not relying on the premise, "My perspective is reliable," in reasoning to that conclusion. One is simply proceeding as if one's perspective is reliable by believing in accordance with how things seem. Second, note that proceeding on such an assumption is absolutely necessary for rational inquiry more generally. How is anyone to prove the reliability of his perspective (or its unreliability for that matter!) without trusting in how things seem, and thus proceeding as if his perspective is reliable? ${ }^{17}$

In the end, there does not seem to be any good argument from the existence of deep and reasonable moral disagreement to the conclusion that Christian moral beliefs are 
subjective or unreliable or rationally ought to be abandoned. At least, there is no argument that should persuade Christians of such things.

\section{Resolving Deep Disagreements}

A final worry for moral perspectivalism centers on the prospects (or the lack thereof) for resolving disagreement. Does perspectivalism eliminate the possibility of fruitful dialogue between Christians and non-Christians? The first thing to note is that this is not an objection to the truth of moral perspectivalism. Some disagreements may be unresolvable. Perhaps that is our lot as finite creatures that know the world in a mediated way. The fact that we do not like these limitations does not mean we do not have them. Unresolvability becomes an objection only when (i) we have reason to believe that certain disputes are resolvable and (ii) moral perspectivalism leads us to expect that they are not. However, no dispute has clearly met both conditions. That is, some disagreements actually are resolvable on moral perspectivalism, and those that are not are not ones that we can reasonably expect to be resolvable.

There are several ways in which rational discourse between those of different perspectivesin this case, Christians and non-Christians-can continue to be fruitful. Even if the data (the appearances) are almost entirely different for non-Christians, the Christian can still point out an internal flaw in their attempt to explain those data. There may, in other words, be internal inconsistencies or tensions within the non-Christian belief system that the Christian can exploit.

Thankfully, however, the appearances are almost never entirely different. There is usually significant commonality in our moral intuitions that can be leveraged into arguments for the Christian position. Human nature is disposed from the get-go to see certain things as good (e.g., life, knowledge, friendship, benevolence, justice, pleasure) and other things as bad (e.g., death, ignorance, loneliness, misanthropy, injustice, pain). While one's appreciation of such things can sometimes be occluded, it is rarely altogether extinguished. Human nature has a way of reasserting itself given enough time. There are, of course, outliers-psychopaths who suffer from a kind of moral blindness-but here the exception proves the rule. Moral traditions, moreover, have mostly arisen out of these natural intuitions, and so preserve them into reflective maturity. One's moral tradition will undoubtably reshape one's natural intuitions, recasting them in their own particular likeness, but the larger point remains. We should expect to find, and usually do see, significant commonality between those of different moral perspectives. This is often enough for rational dialogue in some form to continue. ${ }^{18}$

The previous two strategies operate in a straightforward manner. One simply formulates an argument using only premises that one's interlocutor, on his or her perspective, already accepts. There is, however, another path to resolving disagreement; and that is to alter the perspective itself. You may still give your interlocutor an argument, but it is an argument the premises of which are rationally acceptable only if a shift in perspective occurs. The key, then, is to initiate a gestalt shift within one's interlocutor-to get him to see the world in a new way-and by so doing position him to see the superiority of one's own position to the position previously held. If successful, this stratagem generates evidence for the Christian position rather than simply appealing to evidence one already has.

The transition to the Christian perspective can be encouraged in a variety of ways. Generally speaking, the goal is to get one's interlocutor to "try on" the Christian perspective.

This is not merely to inspect the Christian point of view from the outside, but to imaginatively enter into it, temporarily considering the world as though Christianity were true. C.S. Lewis gets at something close to this distinction with the following example:

I was standing today in a dark toolshed. The sun was shining outside and through the crack at the top of the door there came a sunbeam. From where I stood that beam of light, with the specks of dust floating in it, was the most striking thing in the place. Everything else was almost pitch-black. I was seeing 
the beam, not seeing things by it. Then I moved, so that the beam fell on my eyes. Instantly the whole previous picture vanished. I saw no toolshed, and (above all) no beam. Instead I saw, framed in the irregular cranny at the top of the door, green leaves moving on the branches of a tree outside and beyond that, 90 odd million miles away, the sun. Looking along the beam, and looking at the beam are very different experiences. ${ }^{19}$

When you get someone to see things through the Christian perspective, rather than just looking at it, the perspective has a tendency to stick. The Christian answers to life's fundamental questions, not to mention the framing of those questions themselves, proves intellectually satisfying. It just makes sense to some people. The result is that their own intuitions begin to align more closely with that of the Christian perspective, either gradually or all at once.

You can invite someone into the Christian perspective in multiple ways. Simply stating the Christian position in a cogent theological treatise, if read carefully and charitably, may do the trick. Of course, treatises are rarely read (not to mention carefully or charitably), and so more accessible and intuitive presentations of Christianity-such as C.S. Lewis's Mere Christianity - are often more effective. Narratives also constitute a powerful tool. Stories engage the imagination and so possess great potential for shaping the perspectives of their readers. This is a point explored persuasively by Eleonore Stump (2010) in Wandering in Darkness. Christians, then, might simply invite their conversational partners to read Scripture, or other Christian literature by the likes of Lewis, Tolkien, or Dostoyevsky.

There are other strategies that deserve mentioning. Increased attention is being given to the philosophical study of liturgy. ${ }^{20}$ One aspect that must surely be considered is the ability of liturgy, through careful selection of language, symbol, and gesture, to coax one into a Christian perspective. Finally, the personal example of Christians is one of our most powerful tools. Empathy allows one to project herself inside the mind of another-to look at the world as someone else sees it-in order to make sense of his or her actions and judgments. Empathizing with a Christian, then, requires trying on the Christian perspective; and this, I have suggested, creates an opportunity for that perspective to become one's own.

One may worry whether this is a rational and altogether respectable form of persuasion. It smells of sophistry-empty rhetoric that appeals to the appetites rather than reason. No doubt one can initiate a perspective shift through appeal to the appetites, but that need not be the way of it. Consider Plato. Plato zealously condemns sophistry, yet the dramatic portrayals of Socrates recounted in his dialogues are best understood as attempts not only to engage the audience in reasoning but also to foster within that audience a perspective that acknowledges the authority of reason (for, as Polemarchus says in reply to Socrates, "But could you persuade us if we won't listen?"). Thus, one who reads Plato's Republic receives not only arguments for the superiority of the just life, but a grand Platonic vision of reality from which the strength of these arguments can be appreciated. The attempt is to initiate the reader into a Platonic perspective, which is perhaps one reason why Plato chose to write dialogues rather than treatises (the former being generally more effective in triggering perspective shifts). What Plato is doing here is something more than straightforward, discursive argumentation, but whatever it is, it is not mere sophistry.

On further inspection, one sees that what I have suggested in "trying on" the Christian perspective is not altogether different from what happens all of the time in inference to the best explanation. When one considers the quality of an explanation, one does so by projecting oneself into a perspective from which that explanation is taken to be true. For instance, the detective considers whether the butler committed the murder by envisioning a scenario in which the butler does it and then asking himself whether this scenario makes sense: Is it intrinsically plausible? Does it account for all the evidence? How does it stack up to against alternative explanations? If the envisioned scenario is a compelling one, the detective may undergo a perspective shift and find himself suspecting the butler. This is essentially what the above strategies do. Whether through prose, narrative, liturgy, or 
personal example, each invites the subject to consider the world through the Christian perspective. What makes it stick, however, is when that perspective makes sense to the person, and this is just as rational and respectable a way of being persuaded as any other.

There is, of course, no guarantee that the desired perspective shift will occur. There are many and varied reasons why one's interlocutor might decline to try on the Christian perspective or else fail to be convinced by it-factors encompassing the will as well as the intellect. ${ }^{21}$ The disappointing fact is that there is no cure-all for moral disagreement. Sometimes the parties in a discussion hold different perspectives leading to different conclusions, and neither of those perspectives will budge. However, this provides no objection to moral perspectivalism. To the contrary, it would be a surprise if all moral debates could be resolved simply through more and better reasoning.

The Christian in particular has no reason to object to moral perspectivalism on the basis of irresolvable disagreements. Paul says, "the cross is foolishness to those who are perishing," (1 Corinthians 1: p. 18, NIV) and that "the wisdom of this world is foolishness in God's sight" (1 Corinthians 3: p. 19, NIV). The stark difference between the mindset of Christians and non-Christians should, it seems, lead to instances in which the disagreements between them cannot be argued away.

It may be, as suggested earlier, that the onset of the Christian perspective (or certain elements of it) is an integral part of having faith in God. If so, then these perspectiveshifting strategies can be understood as creating opportunities for the dispensation of faith. Ultimately, faith is a gift from the Spirit, and the Spirit distributes gifts as he wills (1 Corinthians 12: pp. 8-11). This confirms our verdict that the persuasion of non-Christian interlocutors cannot be guaranteed - at least not by any effort on our part. We can do our best to present the Christian position in the manner most conducive to faith, but we can do no more than this. We wait on God for the rest.

\section{Conclusions}

I began this paper by acknowledging the reality of deep and reasonable moral disagreement between Christians and non-Christians. The rest of the paper explains why acknowledging this reality need not cause any serious worry to the Christian. Seemings foundationalism, and the kind of moral perspectivalism that arises from it, provides an explanation of the disagreement that avoids both relativism and skepticism. Nor does it close off the possibility of rational resolution. What it does do is help us better understand the nature of our disagreements and, in turn, how they stand the greatest chance of being resolved.

Funding: This research received no external funding.

Institutional Review Board Statement: Not applicable.

Informed Consent Statement: Not applicable.

Data Availability Statement: Not applicable.

Conflicts of Interest: The author declares no conflict of interest.

\section{Notes}

1 Admittedly, these labels are somewhat infelicitous as non-traditional Christians are sorted into the non-Christian camp. The choice is simply a matter of convenience-it is easier to say "non-Christians" than "those who are not traditional Christians, including non-traditional Christians and those who are not Christian at all." Why focus on traditional Christians rather than on all Christians? For one, the moral judgments of non-traditional Christians are generally more in line with non-Christians than with their traditional brethren. For another, the resolution to the problem of religious disagreement developed in Section 3 will only be acceptable to traditional Christians. Finally, only traditional Christians are likely to be concerned about the challenges to resolving disagreement, since nontraditional Christians are generally indifferent, at best, towards attempts at conversion. Thus, traditonal Christians (TC) and not-TC are the relevant contrast classes.

2 Thomson (1971). 
4 Nietzsche (1886, p. 152).

5 Singer (1979, p. 172).

6 While my focus is on how Christians should respond to moral disagreement with non-Christians, much of what I say will have obvious application to non-Christians (who should also resist the temptation to charge all of their disputants with irrationality) as well as to in-house disagreements within each camp.

7 This formulation of phenomenal conservatism is from Huemer (2007). Huemer first introduces phenomenal conservatism to the literature in Huemer (2001).

8 See McAllister (2018a) for an argument for this view of seemings.

9 At least, emotions are not capable of justifying insofar as they are emotions. Plausibly, some token emotions also constitute token seemings, in which case those emotions would be capable of justifying. They simply would do so by virtue of that which makes them seemings rather than that which makes them emotions.

10 Note that this does not commit anyone to ethical intuitionism as a metaethical theory. That theory makes specific claims about the nature of goodness (such as its being non-natural) and how we intuit things about it that go far beyond what I am claiming here.

11 See Huemer (2005) for some of the many ways in which moral beliefs migsht still be irrational even if moral intuitions grant prima facie justification.

12 Reid (1785, essay 1 , chp. 8, p. 24).

13 Lewis $(1944$, p. 40). Lewis is talking about something else, but the line fits nonetheless.

14 McAllister (2018b, Forthcoming), and Gage and McAllister (2020).

15 Plantinga (2000).

16 See, e.g., Christensen (2007).

17 Alston (1991) argues persuasively that no fundamental belief-forming practices can be verified without reliance on those very practices. For more on the use of one's Christian beliefs to dismiss potential challenges to the reliability of those Christian beliefs, see Moon (2021).

18 It is worth pointing towards MacIntyre's work on this point. Even when we acknowledge the pervasive differences between traditions, it is still possible for an adherent of one tradition to come to recognize the superiority of another tradition. This occurs when one recognizes how the alternative tradition frames things in such a way that better explains anomalies, avoids dead-ends, and handles problems that plague the former tradition. See MacIntyre (1988, 1977).

19 Lewis (1970).

20 See, e.g., Cuneo (2016).

21 Kierkegaard makes this point as effectively as anyone. See Evans (1998).

\section{References}

Alston, William P. 1991. Perceiving God: The Epistemology of Religious Experience. Ithaca: Cornell University Press. Christensen, David. 2007. Epistemology of Disagreement: The Good News. Philosophical Review 116: 187-217. [CrossRef]

Cuneo, Terence. 2016. Ritualized Faith: Essays on the Philosophy of Liturgy. Oxford: Oxford University Press.

Evans, C. Stephen. 1998. Faith Beyond Reason. Grand Rapids: William B. Eerdmans-Lightning Source.

Gage, Logan Paul, and Blake McAllister. 2020. The Phenomenal Conservative Approach to Religious Epistemology. In Debating Christian Religious Epistemology: An Introduction to Five Views on the Knowledge of God. Edited by John M. DePoe and Tyler McNabb. New York: Bloomsbury Academic, pp. 61-81.

Huemer, Michael. 2001. Skepticism and the Veil of Perception. Lanham: Rowman \& Littlefield.

Huemer, Michael. 2005. Ethical Intuitionism. London: Palgrave Macmillan.

Huemer, Michael. 2007. Compassionate Phenomenal Conservatism. Philosophy and Phenomenological Research 74: 30-55. [CrossRef]

Lewis, Clive S. 1944. The Abolition of Man. New York: HarperCollins.

Lewis, Clive S. 1970. Meditation in a Toolshed. In God in the Dock. Grand Rapids: William B. Eerdmans Publishing, pp. $212-15$.

MacIntyre, Alasdair. 1988. Whose Justice? Which Rationality? Notre Dame: University of Notre Dame Press.

MacIntyre, Alisdair. 1977. Epistemological Crises, Dramatic Narrative and the Philosophy of Science. The Monist 60: 453-72. [CrossRef]

McAllister, Blake. 2018a. Seemings as Sui Generis. Synthese 195: 3079-96. [CrossRef]

McAllister, Blake. 2018b. The Perspective of Faith: It's Nature and Epistemic Implications. American Catholic Philosophical Quarterly 92: 515-33. [CrossRef]

McAllister, Blake. Forthcoming. The Partiality of Faith. Australasian Philosophical Review.

Moon, Andrew. 2021. Circular and Question-Begging Responses to Religious Disagreement and Debunking Arguments. Philosophical Studies 178: 785-809. [CrossRef]

Nietzsche, Freidrich. 1886. Beyond Good and Evil. Translated by Judith Norman. Cambridge: Cambridge University Press. 
Plantinga, Alvin. 2000. Warranted Christian Belief. Oxford: Oxford University Press.

Reid, Thomas. 1785. Essays on the Intellectual Powers of Man. Edited by Derek R. Brookes. University Park: Pensylvania State University Press.

Singer, Peter. 1979. Practical Ethics. Cambridge: Cambridge University Press.

Stump, Eleonore. 2010. Wandering in Darkness: Narrative and the Problem of Suffering. Oxford: Oxford University Press.

Thomson, Judith Jarvis. 1971. A Defense of Abortion. Philosophy and Public Affairs 1: 47-66. 